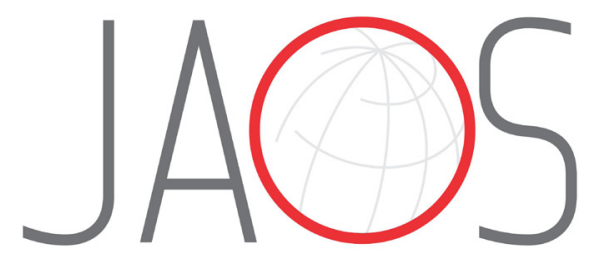
JOURNAL OF APPLIED ORAL SCIENCE

\title{
Effect of dental bleaching on pulp oxygen saturation in maxillary central incisors - a randomized clinical trial
}

\section{Abstract}

Lorena Ferreira LIMA ${ }^{1}$

Ana Helena Gonçalves de ALENCAR ${ }^{1}$

Daniel de Almeida DECURCIO' ${ }^{1}$

Julio Almeida SILVA ${ }^{1}$

Isabella Negro FAVARÃO ${ }^{1}$

Marco Antônio Zaiden LOUREIRO ${ }^{1}$

Fernando Branco BARLETTA ${ }^{2}$

Carlos ESTRELA ${ }^{1}$ iD

Submitted: August 29, 2018 Modification: November 5, 2018

Accepted: November 7, 2018

Corresponding address: Carlos Estrela

Universidade Federal de Goiás Faculdade de Odontologia. Praça Universitária $\mathrm{s} / \mathrm{n}$ - Setor Universitário Zip Code 74605-220 - Goiânia - GO - Brasil. Phone: +55-62-3209-6254 e-mail: estrela3@terra.com.br
Objective: To assess pulp oxygen saturation levels $\left(\mathrm{SaO}_{2}\right)$ in maxillary central incisors after dental bleaching. Materials and Methods: 80 participants (160 teeth) were randomly allocated to four groups: G1 In-office bleaching with two applications of 35\% hydrogen peroxide (HP) (20 minutes), followed by at-home bleaching with $10 \%$ carbamide peroxide (CP) (2 hours/day for 16 days); G2 - Same protocol as G1, plus desensitizing toothpaste; G3 - Inoffice bleaching with 35\% HP and one application of placebo gel (20 minutes), followed by at-home bleaching with 10\% CP (2 hours/day for 16 days); and G4 - Same protocol as G3, plus desensitizing toothpaste. Pulp $\mathrm{SaO}_{2}$ levels were measured before (TO) and immediately after (T1) in-office bleaching; on the $5^{\text {th }}(\mathrm{T} 2), 8^{\text {th }}(\mathrm{T} 3), 12^{\text {th }}(\mathrm{T} 4)$, and $16^{\text {th }}$ days of at-home bleaching (T5); and on the $7^{\text {th }}$ (T6) and $30^{\text {th }}$ (T7) days. Mean (SD) pulp $\mathrm{SaO}_{2}$ levels were compared within groups by generalized estimating equations (GEE) and Student's t-test $(\mathrm{P}<0.05)$. Results: Mean pulp $\mathrm{SaO}_{2}$ at $\mathrm{T0}$ was $84.29 \%$ in $\mathrm{G} 1,84.38 \%$ in $\mathrm{G} 2,84.79 \%$ in $\mathrm{G} 3$, and $85.83 \%$ in G4. At T1, these values decreased to $81.96 \%, 82.06 \%, 82.19 \%$, and $81.15 \%$ in G1, G2, G3, and G4 respectively, with significant difference in $\mathrm{G} 4(\mathrm{P}<0.05)$. During home bleaching, pulp $\mathrm{SaO}_{2}$ levels varied in all groups, with $86.55 \%, 86.60 \%$, $85.71 \%$, and $87.15 \%$ means at T7 for G1, G2, G3, and G4, respectively; $\mathrm{G} 2$ presented significant difference $(\mathrm{P}<0.05)$. Conclusions: $\mathrm{Pulp} \mathrm{SaO}_{2}$ level in maxillary central incisors was similar at baseline, reducing immediately after in-office bleaching, regardless of using desensitizing toothpaste and increasing at 30 days after dental bleaching.

Keywords: Dental bleaching. Dental pulp. Clinical trial. Tooth bleaching.

'Universidade Federal de Goiás, Faculdade de Odontologia, Departamento de Ciências Estomatológicas, Goiânia, Goiás, Brazil.

2Universidade Luterana do Brasil, Faculdade de Odontologia, Departamento de Ciências Estomatológicas, Canoas, Rio Grande do Sul, Brazil. 


\section{Introduction}

The search for a smile that conveys health and beauty is a common reason for seeking dental care. Interpersonal relationships and self-esteem also seem to be associated with the search for dental bleaching. The preference for whitening is justified because it is considered a conservative, safe, and effective treatment. ${ }^{1}$

There are two types of dentist-supervised bleaching techniques: at-home or in-office bleaching, ${ }^{2}$ and both techniques usually employ products based on hydrogen peroxide or carbamide peroxide. ${ }^{3}$ However some authors have proposed a combined bleaching technique ${ }^{1}$ to combine the benefits of both techniques, such as the minimal adverse effects of at-home bleaching ${ }^{4}$ and the faster whitening potential of inoffice bleaching. ${ }^{2}$

Despite the aesthetic benefits, tooth sensitivity (TS) is a very common side effect ${ }^{5}$ of dental bleaching, causing discomfort in two-thirds of patients who undergo dental bleaching. ${ }^{6}$ A recent multivariable logistic regression analysis reported a $51 \%$ probability of developing TS after home bleaching and $62.9 \%$ after in-office bleaching. ${ }^{1}$ Given this context, some authors have proposed changes in bleaching techniques, such as the reduction of contact time of bleaching gels in in-office procedures, ${ }^{7,8}$ the addition of substances to bleaching agents, and the use of desensitizing agents or dentifrices. ${ }^{3,9}$

Studies have discussed the penetration of bleaching agents into the pulp chamber. ${ }^{10,11}$ Hydrogen peroxide and its products have the ability to rapidly diffuse through the mineralized tissues of the tooth, which is attributed to the low molecular weight of these substances and to the permeability of enamel and dentin. ${ }^{10,11}$ The volume of bleaching agent that enters the pulp chamber depends on the peroxide concentration, ${ }^{8,10}$ the duration of contact with the tooth structure, ${ }^{8,12}$ the enamel and dentin thickness of whitened teeth, ${ }^{13}$ and the presence of restorations. ${ }^{11}$

Hydrogen peroxide after penetrating the pulp chamber comes into contact with the dental pulp, crosses cell membranes and dissociates into free radicals in the cytoplasm, resulting in the establishment of an oxidative stress state. ${ }^{8,14}$ The adverse effects of oxidative stress correlate negatively with the enamel/dentin thickness of the whitened tooth. Therefore, small teeth such as mandibular incisors are more susceptible to oxidative damage, being more amenable to diffusion of the bleaching agent into the pulp chamber. ${ }^{13}$ A histopathological study demonstrated pulpitis and superficial necrosis in incisors of young patients after in-office bleaching. In premolars, changes were similar to those observed in unbleached teeth. ${ }^{13}$ High macrophage density, collagen degradation, and inflammatory infiltration of the dental pulp were observed in molars 7 days after completion of in-office bleaching procedures. ${ }^{15}$

The clinical diagnosis of pulp status remains highly challenging. Due to being located within a closed cavity, the dental pulp is inaccessible to direct inspection. Thermal, electrical, and cavity tests are usually employed to assess its clinical condition. The limitations of these pulp sensitivity tests include the possibility of false-positive and false-negative results. ${ }^{16}$

Various electronic modalities have assessed the utility of determining pulp status, including spectrophotometry, laser Doppler flowmetry, and pulse oximetry. ${ }^{16,17}$ Pulse oximetry has been widely used in medical practice. In dentistry, it is considered a promising resource for measuring oxygen saturation levels $\left(\mathrm{SaO}_{2}\right)$ in dental pulps. ${ }^{16,17}$

Oxygen is carried in the body bound to hemoglobin, an iron-containing protein present in red blood cells. Each molecule of hemoglobin can carry up to four molecules of oxygen, this state is described as "saturated" with oxygen (100\%). A healthy individual, with healthy lungs, breathing ambient air, shows arterial $\mathrm{SaO}_{2}$ levels between $95 \%$ and $100 \% .{ }^{19}$ In the teeth, the mean values of $\mathrm{SaO}_{2}$ recorded by pulse oximetry have ranged from $75 \%^{19}$ to $92.60 \%^{20}$ in healthy pulp and below $74.6 \%$ in necrotic pulp. ${ }^{21}$ These levels seem to vary according to tooth and age group. ${ }^{22}$ In teeth with inflamed or necrotic pulp, the behavior of this parameter remains unclear. ${ }^{17,21,23}$

Pulse oximetry seems to be an innovative technology for endodontic diagnosis, which would enable the analysis of pulp status during operative dentistry and real-time monitoring of pulp vitality. The measurement of $\mathrm{SaO}_{2}$ levels in pulp tissue may provide new perspectives for more precise diagnoses of pulp status, which would certainly prevent unnecessary endodontic interventions and provide an evidence base for additional clinical studies. Given this context, this study aimed to assess $\mathrm{SaO}_{2}$ levels in the pulp of healthy human maxillary central incisors and their response to combined dental bleaching. 


\section{Materials and methods}

This study was approved by the Research Ethics Committee of Universidade Federal de Goiás, Brazil (pr.\# 52047115.2.0000.5083), and was conducted from February to June 2016. The sample size was calculated in WINPEPI. Considering a 95\% confidence level, a 5.0 standard deviation, and a 1.0 margin of error, the minimum sample size was estimated at 99 teeth (i.e., 25 teeth per group). Considering two maxillary central incisors per participant, the exclusion of $20 \%$ of participants due to inclusion and exclusion criteria, and a $20 \%$ attrition rate during follow-up, an initial sample of 100 individuals was defined. The patients included in the study were asked to provide written informed consent required for studies on human beings.

\section{Study design}

This was a randomized, triple-blind (researchers, participants, and outcome assessors) clinical trial with equal allocation. The experimental design followed the CONSORT guidelines.

\section{Participant selection and inclusion and exclusion criteria}

Clinical evaluation was performed in 325 individuals recruited for dental whitening. Of these, 108 individuals met the eligibility criteria, and underwent a clinical examination. After an interview and history evaluation, the patients underwent an intraoral examination that included inspection, palpation, percussion, and evaluation of periodontal health (absence of mobility, recession, and periodontal attachment loss). Cold thermal pulp testing was performed with the Green Endo Ice refrigerant $\left(-26.2^{\circ} \mathrm{C}\right.$, Hygenic, Ohio, USA) under cotton-roll insulation. To evaluate pulp sensitivity, the time to patient response in seconds was recorded using a digital timer, and the sensitive stimulus (pain) was recorded on an analogue scale from 0 to 10 , with 0 being no pain and 10 representing severe pain. The test was considered negative if there was no response after two 15-second applications of the refrigerant gas, with a 2-minute interval between applications. Periapical radiography was performed to assist in the diagnosis.

Of the 108 subjects examined, five considered the duration of the experiment overlong, one reported hypersensitivity to the cold thermal test, and 14 did not meet the inclusion criteria. The inclusion criteria were ages between 18 to 39 years, healthy maxillary central incisors, a normal periodontal ligament space, no pulp stones or obliterations, no root resorption or fracture, good periodontal health, and complete root formation. Patients who had previously undergone dental bleaching or whitening, smokers, pregnant women, those with a history of cardiovascular disease, those currently on any systemic medication or drugs, those with a history of occlusal or dental trauma, and those with negative pulp tests were excluded.

\section{Random allocation and blinding}

A computerized sealed-envelope randomization method was used by an investigator who was not involved in the clinical procedures to allocate the 80 selected participants across four groups. These groups were coded G1, G2, G3, and G4. Patients were not informed of their group allocation. Codes were placed into opaque white envelopes, which were sealed and stored with each participant's clinical record. Unblinding was performed at the end of the study.

All clinical interventions were performed by the same practitioner, a specialist in restorative dentistry who was blinded to group allocation. All materials for the bleaching procedure were prepared by another researcher so the intervention product and placebo were indistinguishable. Measurement of pulp oxygen saturation level before, during, and after bleaching procedures was performed by another blinded researcher (a endodontics specialist).

\section{Clinical intervention}

One week before starting the bleaching procedure, participants were advised on oral hygiene and dietary habits. During this visit, impressions of both dental arches were obtained with type II alginate (Plastalgin, Zhermack, NJ, USA), disinfected, and cast with type III dental stone (Asfer Indústria, SP, Brazil). These casts were then used to fabricate $1 \mathrm{~mm}$ thick silicone whitening trays in a vacuum-forming machine (Essence Dental VH, SP, Brazil). During this visit, participants also received an unidentified tube containing toothpaste (Sorriso Fresh, Colgate Palmolive, SP, Brazil) with or without desensitizer ( $8 \%$ arginine and calcium carbonate), depending on their group allocation. They were then instructed to use only this toothpaste whenever brushing. Participants were also advised to manually rub the toothpaste onto all teeth for 1 minute and rinse with plenty of water before 
applying the trays containing home bleaching gel.

In-office bleaching procedures were performed following the manufacturer's instructions, after polishing with pumice and water. To protect the oral soft tissues, the lip and tongue retractor and dental dam provided with the Total Blanc Office kit (Nova DFL, RJ, Brazil) were used. Hydrogen peroxide gel (35\%) was applied onto the vestibular surface of the anterior teeth and premolars, left to act for the time specified for each group, and suctioned. Teeth were then rinsed with water and dried with cotton.

The following bleaching procedures were performed: G1 - Single-visit in-office bleaching with two applications of $35 \%$ hydrogen peroxide (Total Blanc Office, Nova DFL, RJ, Brazil) for 20 minutes each, followed by at-home bleaching with $10 \%$ carbamide peroxide (Total Blanc Home, Nova DFL, $\mathrm{RJ}$, Brazil), applied in an individual tray for 2 hours a day on 16 consecutive days, using toothpaste without desensitizer; G2 - In-office and at-home bleaching with the same protocol used in G1, but instead using toothpaste with a desensitizing agent; G3 - Singlevisit in-office bleaching with a single application of $35 \%$ hydrogen peroxide (Total Blanc Office, Nova DFL, RJ, Brazil) for 20 minutes and a single application of placebo gel ( $K Y$, Johnson \& Johnson, NJ, USA) for 20 minutes, followed by at-home bleaching with $10 \%$ carbamide peroxide (Total Blanc Home, Nova DFL, RJ, Brazil), applied in an individual tray for 2 hours a day on 16 consecutive days, using toothpaste without desensitizer; and G4 - In-office and at-home bleaching with the same protocol used in G3, but instead using toothpaste with a desensitizing agent.

\section{Pulp oxygen saturation level}

Fingertip and dental pulp $\mathrm{SaO}_{2}$ levels were measured using a BCI portable pediatric pulse oximeter (model 3301, Smiths Medical PM Inc., USA) and a SYS 103 sensor, with a specially made adapter (18 $\mathrm{mm}$ high, $18 \mathrm{~mm}$ wide, and $11 \mathrm{~mm}$ thick), as proposed by Giovanella, et al. ${ }^{24}$ (2014) (Figure 1).

Measurement of pulp $\mathrm{SaO}_{2}$ level was performed under cotton-roll isolation and constant suction to ensure dryness of the dental surfaces involved, and in the absence of any reflected light. Participants were placed in the supine position and instructed to remain still during the vitality test. The sensor with the prefabricated adapter was placed onto the tooth of interest so the emitted light reached the middle third of the crown, and the emitting diode and photodetector were coplanar. Two measurements were obtained, one for the first 1 minute after sensor placement onto the tooth, and the second, 1 minute after the first measurement; these measurements were averaged. All measurements were obtained at a controlled room temperature of $24^{\circ} \mathrm{C}\left( \pm 1^{\circ} \mathrm{C}\right)$.

Pulp $\mathrm{SaO}_{2}$ was evaluated 1 week before application of the bleaching agent (TO); immediately after the inoffice bleaching session (T1); on the fifth day (T2), eighth day (T3), twelfth day (T4), and sixteenth day of home bleaching (T5); and one week (T6) and one month (T7) after the end of all bleaching procedures. Oxygen saturation levels were also evaluated in 10 endodontically treated teeth, which served as negative controls.

\section{Cold thermal pulp testing}

Pulp sensitivity testing was performed during the first visit as described above, and repeated 30 days (T7) after completion of the bleaching procedures, using the same protocol.

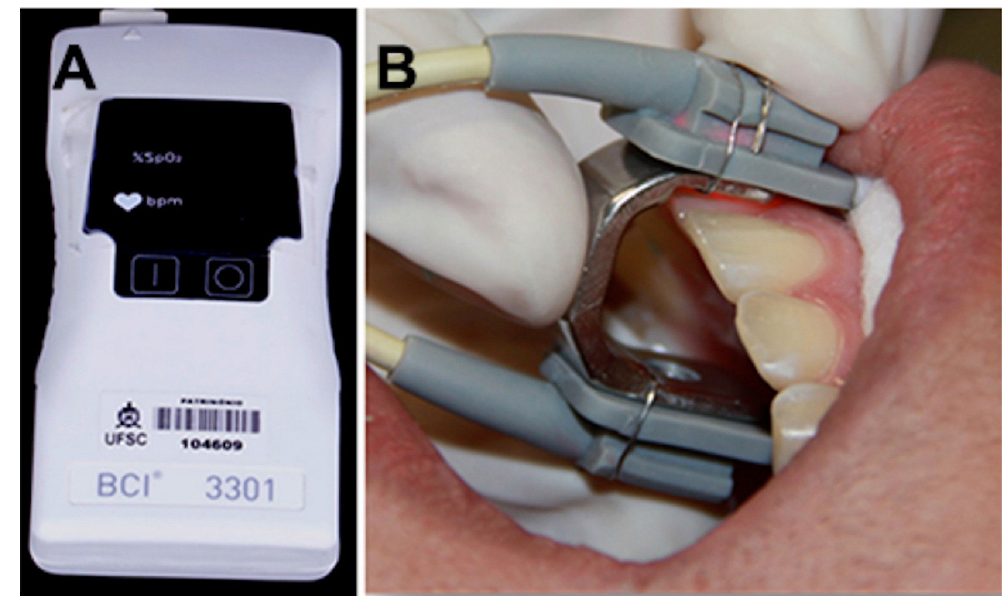

Figure 1-A) Pulse oximeter and B) sensor with specially manufactured adapter 


\section{Statistical analysis}

Mean fingertip and pulp oxygen saturation levels were described as means and standard deviations. The time points and pulp $\mathrm{SaO}_{2}$ levels in each group were compared using the generalized estimating equations (GEE) model. Student's t-test for paired samples was used to compare the overall means at baseline (TO) and 30 days after tooth bleaching (T7). The significance level was set at $5 \%$.

\section{Results}

Of the 80 subjects selected for this study, $21.25 \%$ withdrew during the clinical intervention period, and $2.5 \%$ were excluded due to severe TS. Pulp $\mathrm{SaO}_{2}$ levels were evaluated in 60 subjects (120 maxillary central incisors) before, during, and after combined dental bleaching (Figure 2).

Demographic and clinical characteristics of the subjects are shown in Table 1. Mean pulp oxygen saturation values measured in each group at baseline (T0), immediately after in-office bleaching (T1), during at-home bleaching (T2, T3, T4, and T5), one week (T6), and one month (T7) after the end of the bleaching treatment are presented in Table 2.

In all groups, the mean pulp $\mathrm{SaO}_{2}$ level decreased from T0 to T1, varied somewhat from T1 to T6, and increased from T6 to T7. Table 2 shows that, in G2, there was a significant increase in this value from T0 to T7 $(P<0.05)$, while in $\mathrm{G} 4$, there was a significant decrease from T0 to T1 $(P<0.05)$. Figure 3 illustrates variations in pulp $\mathrm{SaO}_{2}$ levels within each group at baseline, during the in-office and at-home bleaching procedures, and after all bleaching treatments had been completed.

The baseline (TO) mean pulp oxygen saturation level in the overall sample $(n=120)$ was $84.76 \%$. Thirty days after completion of the bleaching procedures (T7), this level had increased significantly to $86.52 \%$ $(P<0.05)$. All teeth responded positively to the cold thermal pulp test at T7. None of the 10 endodontically treated teeth (negative controls) had a measurable pulp $\mathrm{SaO}_{2}$.

\section{Sample selection}

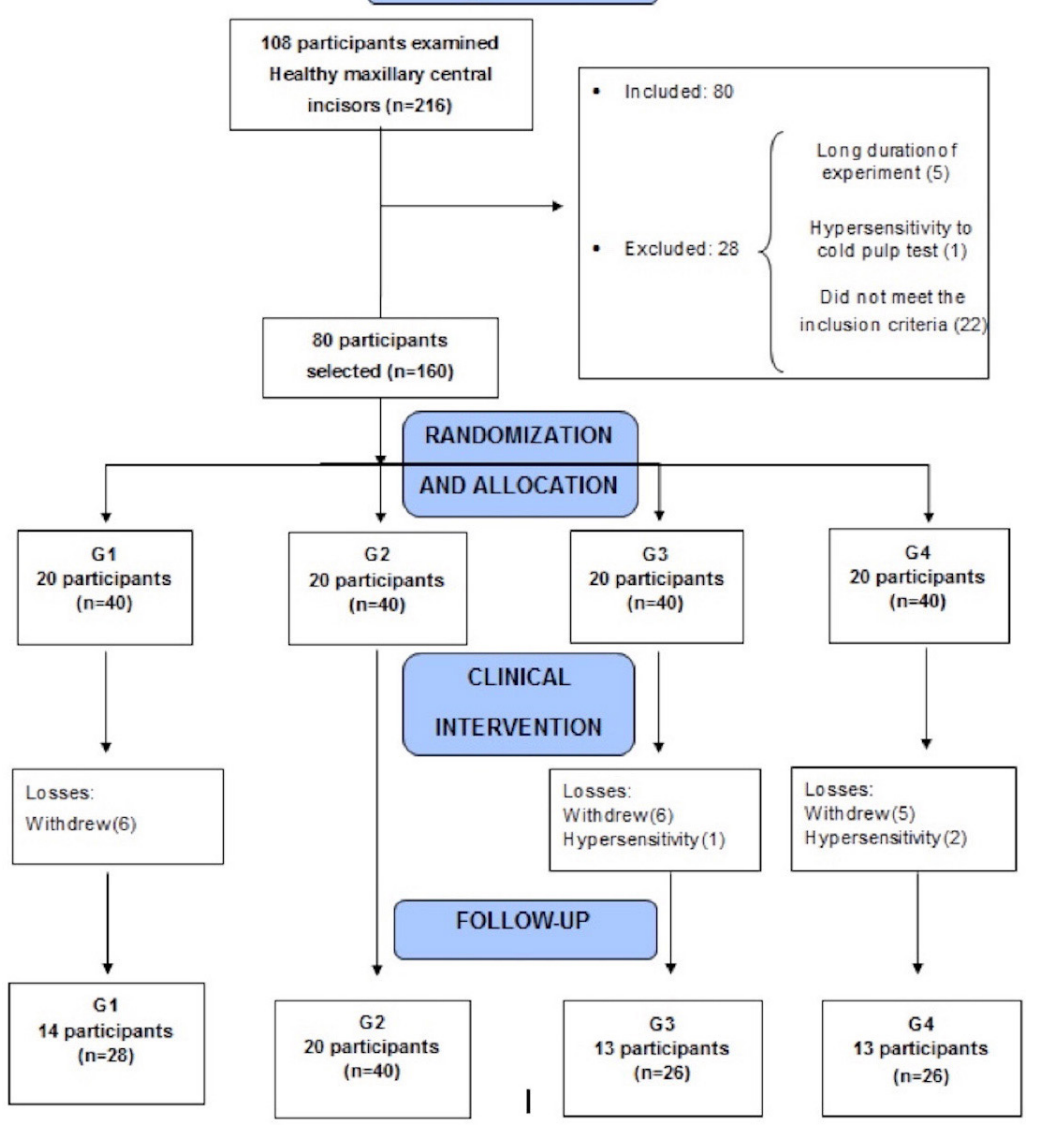

Figure 2- Flow diagram of study inclusion 
Table 1- Demographic and clinical characteristics of study participants

\begin{tabular}{lcccc}
\hline \multicolumn{1}{c}{ Participants } & Group 1 & Group 2 & Group 3 & Group 4 \\
& $\mathbf{1 4}$ & $\mathbf{2 0}$ & $\mathbf{1 3}$ & $\mathbf{1 3}$ \\
\hline Sex (\%) & & & & 53.85 \\
Women & 57.14 & 75.0 & 61.54 & 46.15 \\
Man & 42.86 & 25.0 & 38.46 & $18-23$ years \\
Age group & $18-24$ years & $18-23$ years & $18-27$ years & 0 \\
Systemic disease & 0 & 0 & 0 & 97.34 \\
Mean fingertip oxygen saturation, \% & 97.48 & 96.80 & 97.12 & 26 \\
Healthy maxillary central incisors, $n$ & 28 & 40 & $100 \%$ & $100 \%$ \\
\hline Positive thermal pulp test (cold) & $100 \%$ & $100 \%$ & & 26 \\
\hline
\end{tabular}

Table 2- Mean pulp oxygen saturation and difference (\%) at baseline (T0) and during and after dental whitening procedures in each experimental group

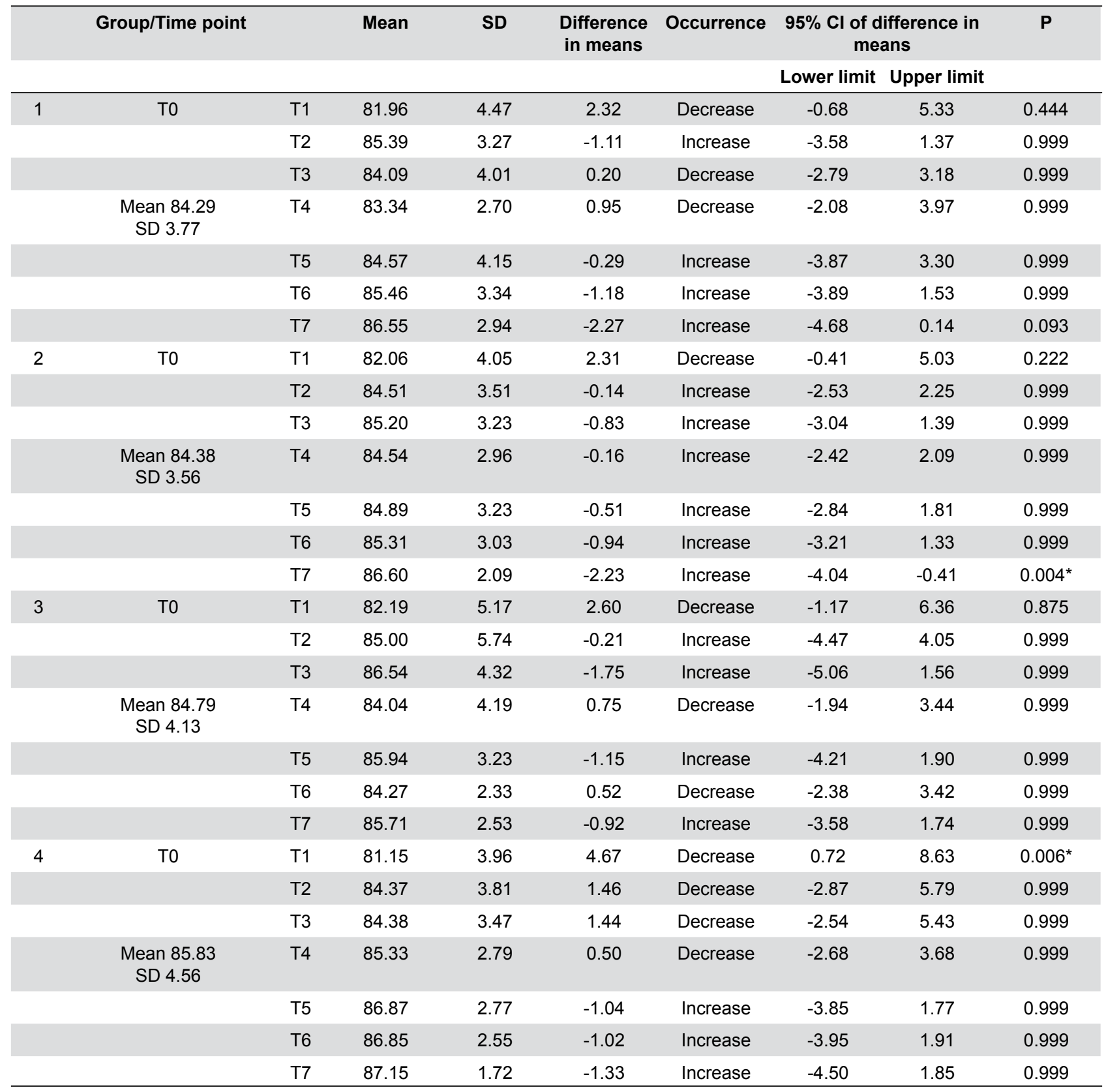

(SD, standard deviation; 95\% Cl: 95\% confidence interval for difference in means; *Statistically significant difference) 


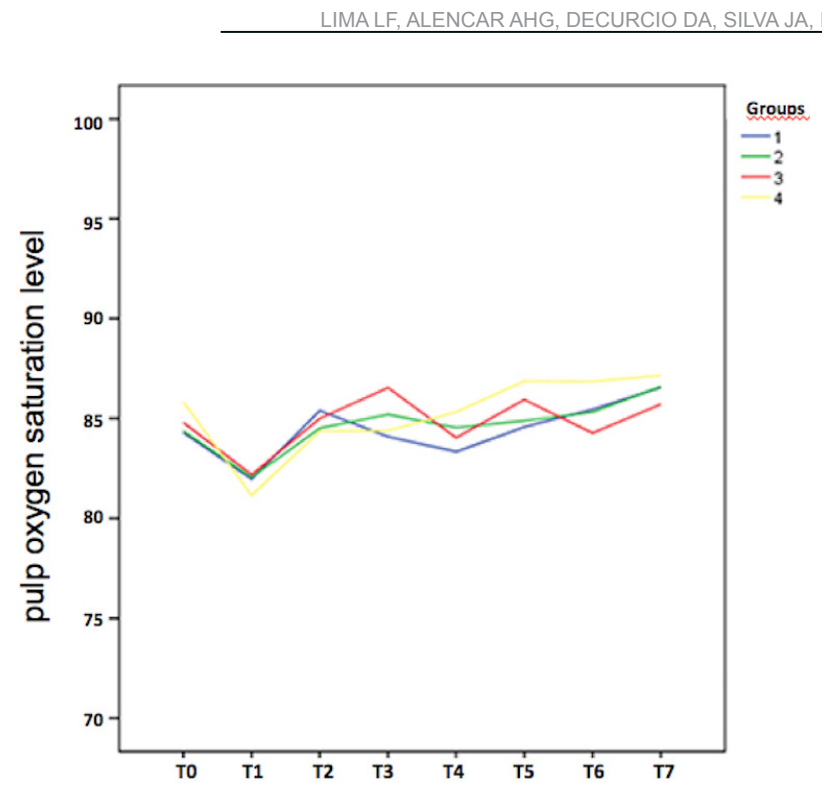

Figure 3- Graphical representation of pulp oxygen saturation level (\%) at baseline, variations observed during whitening procedures, and levels at the end of the intervention in Group 1 (blue), Group 2 (green), Group 3 (red), and Group 4 (yellow)

\section{Discussion}

The mean baseline pulp $\mathrm{SaO}_{2}$ level in this sample of 120 healthy maxillary central incisors was $84.76 \%$. This value is higher than the $81.25 \%$ reported by Stella, et al. ${ }^{25}$ (2015) in an analysis of 110 maxillary central incisors, and similar to the $84.80 \%$ reported by Bargrizan, et al. ${ }^{26}$ (2016) in a sample of 190 healthy central incisors. Oxygen saturation values higher than those of this study $(92.60 \%)$ were measured in maxillary incisors by Kataoka, et al. ${ }^{18}$ (2016). In a critical review of clinical trials using pulse oximetry, Bruno, et al. ${ }^{23}$ (2014) reported an $87.73 \%$ average saturation level in 288 maxillary central incisors. Anatomical variations and differences in sample size may justify the heterogeneity of these results.

Studies have reported variability according to different age ranges, such as from 9 to 14 years, ${ }^{26}$ 15 to 40 years, ${ }^{16,19,25} 15$ to 55 years, $^{23}$ and 35 to 65 years. ${ }^{20}$ In this study, participants aged 18 to 27 years were selected. The discrepancy in baseline $\mathrm{SaO}_{2}$ levels compared to previous studies could also be attributed to these differences in the evaluated age group. Estrela, et al. ${ }^{22}$ (2017) reported lower pulp $\mathrm{SaO}_{2}$ levels $(80.0 \%)$ in healthy premolars of patients aged 40 to 44 years when compared to those measured in patients aged 20 to 24 years $(89.71 \%)$. This reduction may be justified by the increase in dentin thickness that occurs with aging. ${ }^{27}$

In this study, after an in-office bleaching session (T1) with 35\% hydrogen peroxide for 20 minutes, a decrease was observed in pulp $\mathrm{SaO}_{2}$ level when compared to baseline (T0): $81.96 \%$ in $\mathrm{G} 1,82.06 \%$ in G2, $82.19 \%$ in $\mathrm{G} 3$, and $81.15 \%$ in G4, with a significant difference in G4. Cartagena, et al. ${ }^{28}$ (2015), using laser Doppler flowmetry, reported a reduction in pulp blood flow in the maxillary central incisors immediately after an office bleaching session with application of $35 \%$ hydrogen peroxide gel for 15 minutes. This decrease in blood flow may explain the reduction in $\mathrm{SaO}_{2}$ levels detected in our study.

Hydrogen peroxide and its products have been shown to rapidly diffuse in teeth with reduced dentin thickness - like the incisors -, causing oxidative stress to the pulp; this damage is proportional to the duration of contact and concentration of the bleaching gel. ${ }^{8,12}$ One of the side effects of oxidative stress is the formation of reactive oxygen species (ROS), which cause damage to lipids, nucleic acids, and proteins. Oxidative stress increases when the concentration of ROS exceeds the ability of cells to remove them and repair damage. Depending on the intensity of oxidative stress, the affected cells can suffer membrane ruptures and death. Cell death releases lysosomal enzymes, resulting in extensive tissue damage. ${ }^{29}$ In vivo, oxidative stress triggers an inflammatory response. ${ }^{14}$ Benetti, et al. ${ }^{30}$ (2018) observed that IL-6 and IL-17 participated in the inflammatory process occurring in rat pulp tissue after tooth bleaching, particularly in early periods. Immunolabelling was greater with increased $\mathrm{H}_{2} \mathrm{O}_{2}$ concentration and was accompanied by the prolonged activation of $\mathrm{CD} 5$-positive cells.

In dental pulp, as in other tissues, inflammation increases blood flow and vascular permeability. However, because the inflammatory process is contained within rigid walls and access to vascularization occurs only through the apical foramen, intrapulpal pressure rises rapidly, with vessel compression and a consequent decrease in pulp blood flow, ${ }^{31,32}$ which explains the reduction in $\mathrm{SaO}_{2}$ levels detected in this study. According to Alghaithy \& Qualtrough ${ }^{33}$ (2017), changes in $\mathrm{SaO}_{2}$ during inflammatory processes in the pulp may be related to increased acidity and metabolic rate, which are determinants of hemoglobin deoxygenation.

Studies under hypoxic conditions have been performed with dental pulp cells in vitro. ${ }^{32,34}$ Ohzeki and Takahashi ${ }^{35}$ (1980) suggested that degenerative changes in the dental pulp were consequences of hypoxia, whereas Wang, et al. ${ }^{32}$ (2010) did not observe 
any direct damage to pulp cells in this setting. Further clinical studies are needed to evaluate the effects of declining oxygen saturation levels on the dental pulp.

The significant reduction in $\mathrm{SaO}_{2}$ level from baseline is particularly noteworthy since this study was performed on healthy, young teeth, with a favorable pulp status and ample perspectives for reoxygenation after restoration of normal blood flow. However, in teeth with restorations there is a possibility of significant enough reductions in pulp oxygen saturation level following bleaching procedures to lead to extensive and irreversible tissue damage. .6,37 $^{36}$

Shorter application times and lower bleaching agent concentrations may minimize the toxic effects of hydrogen peroxide on pulp tissue. ${ }^{12}$ In this study, one or two in-office, 20-minute applications of bleaching gel, without prior use of desensitizing toothpaste, did not lead to a significant change in pulp oxygen saturation levels. The reduction in saturation was significant in the group that received desensitizer toothpaste after a single in-office application of bleaching gel. Given the existence of an associaiton between the permeability of exposed dentin and sensitivity, many treatment approaches have endeavored to occlude the oral ends of the dentinal tubules using desensitizing agent in dentifrice formulations. ${ }^{6}$ However, this result showed that the use of desensitizing agents did not prevent penetration of hydrogen peroxide into the pulp which corroborates the findings of Soares, et al.12 (2013).

Pulp $\mathrm{SaO}_{2}$ levels varied during the home bleaching period ( $T 2$ to $T 5$ ), although higher than at $\mathrm{T} 1$. Studies conducted after home bleaching showed that, in contact with the dental surface, carbamide peroxide dissociates and releases only $3.3 \%$ of its total hydrogen peroxide concentration. This release occurs slowly and gradually, preventing the immediate penetration of large amounts of hydrogen peroxide into the pulp chamber. ${ }^{38}$ This may explain the variations in pulp oxygen saturation observed in this study during home bleaching, at levels close to those measured at baseline (TO).

On the $30^{\text {th }}$ day after the end of the bleaching sessions (T7), mean pulp $\mathrm{SaO}_{2}$ was significantly higher $(86.52 \%)$ than at baseline $(84.76 \%)$. Soares, et al. ${ }^{32}$ (2015) demonstrated that pulp cells exposed to bleaching protocols and suffering from reduced oxidative stress were able to proliferate significantly over time, with a three- to fourfold recovery of viability 3 days after bleaching procedures. Cartagena, et al. ${ }^{28}$
(2015), using laser Doppler flowmetry, showed an increase in pulp blood flow to levels above baseline 7 days after the end of bleaching procedures in healthy central incisors.

Physiological blood flow in the dental pulp is approximately $0.4-0.5 \mathrm{~mL} / \mathrm{min} / \mathrm{g}$, a rate similar to that of the brain and lower than those of the heart or kidney. ${ }^{31}$ When ischemia is transient, pulp viability is generally restored by reoxygenation following increased blood flow. Hypoxia can increase the mitochondrial and proliferative function of pulp cells, ${ }^{34}$ perhaps enough to increase the angiogenic potential of human pulp cells. ${ }^{39}$ The resident stem-cell population of the dental pulp is critical in the regeneration of the dentin-pulp complex. ${ }^{14} \mathrm{Vaz}$, et al. ${ }^{15}$ (2016) reported an increase in the number of blood vessels 7 days after completion of bleaching procedures in molars. Further research into the biological behavior of dental pulp cells under hypoxic conditions is needed.

Considering the challenges involved in the diagnosis of pulp status, pulse oximetry has proven to be an important resource for clinical use, as it is non-invasive, precise, direct, quantitative, and userfriendly. ${ }^{17,23}$ Several limitations can lead to changes in oxygen saturation measurements, including systemic blood pressure and drug use; however, a careful patient history analysis and blood pressure measurement can minimize the impact of these variables. Factors such as equipment calibration, ambient temperature, incident light, and patient movement, which also interfere with readings, ${ }^{28}$ can be mitigated by obtaining measurements in temperature-controlled rooms, with the lights off, in duplicate, and for a 30-second period. ${ }^{24}$ Dental morphology aspects involved in variability in measurements can be controlled by stratifying analyses by tooth type and age range. All of these factors were carefully considered in our study. Some factors, however, are beyond the reach of the clinician's control, such as individual variations in blood flow and neurovascular response, differences in the optical properties of the dental structure, and the presence of surrounding tissues.

In addition, using pulse oximeters for pulp $\mathrm{SaO}_{2}$ measurement requires the fabrication of special adapters for fingertip sensors since there are no commercial models specifically produced for teeth, which makes it difficult to keep the emitter and receiver diodes parallel. ${ }^{23,33}$ Currently, the distance between the emitting and receiving diodes represents 
the greatest disadvantage in pulse oximetry equipment because of its substantial influence on the signal-tonoise ratio. ${ }^{28,33}$

Oxygen is essential for the aerobic production of cellular energy sources such as adenosine triphosphate (ATP) for mitochondria, and cell activities during tissue repair are directly related to tissue oxygen levels. In the brain, when blood flow decreases to levels under $40 \%$ of control values and it is not restored within three minutes, aerobic metabolism causes irreversible tissue damage due to lack of energy. ${ }^{40}$ The dental pulp is surrounded by hard tissue and only has access to vasculature through small openings at the root apex, which makes it susceptible to hypoxia. Decreased pulpal blood flow has been reported to cause severe pulp damage. ${ }^{41}$ According to Ueno, et al. ${ }^{42}$ (2006), when pulp cells were exposed to hypoxia for periods of 24 hours there was interruption of cell growth and death was detected. Under severe hypoxia conditions, the cells seem to not survive, initiating events that lead to cell death by apoptosis. ${ }^{43}$ Therefore, monitoring pulp oxygen saturation levels before, during, and after tooth bleaching procedures is fundamental.

\section{Conclusion}

The pulp $\mathrm{SaO}_{2}$ level in maxillary central incisors was similar at baseline, reducing immediately after inoffice bleaching, regardless of the use of desensitizing toothpaste and increasing at 30 days after dental bleaching.

\section{Acknowledgements}

The authors declare no conflicts of interest

\section{References}

1- Rezende M, Loguercio AD, Kossatz S, Reis A. Predictive factors on the efficacy and risk/intensity of tooth sensitivity of dental bleaching: a multi regression and logistic analysis. J Dent. 2016;45:1-6.

2- De Geus JL, Wambier LM, Kossatz S, Loguercio AD, Reis A. At-home vs In-office bleaching: a systematic review and meta-analysis. Oper Dent. 2016;41(4):341-56.

3- Maran BM, Burey A, Paris Matos T, Loguercio AD, Reis A. In-office dental bleaching with light vs. without light: a systematic review and meta-analysis. J Dent. 2018;70:1-13.

4- Soares DG, Ribeiro AP, Sacono NT, Coldebella CR, Hebling J, Costa CA. Transenamel and transdentinal cytotoxicity of carbamide peroxide bleaching gels on odontoblast-like MDPC-23 cells. Int Endod J. $2011 ; 44(2): 116-25$.
5- Haywood VB. Treating sensitivity during tooth whitening. Comp Cont Educ Dent. 2005;26(9 Suppl 3):11-20.

6- Markowitz K. Pretty painful: why does tooth bleaching hurt? Med Hypotheses. 2010;74(5):835-40.

7- Kose C, Calixto AL, Bauer JR, Reis A, Loguercio AD. Comparison of the effects of in-office bleaching times on whitening and tooth sensitivity: a single blind, randomized clinical trial. Oper Dent. 2016;41(2):138-45. 8- Soares DG, Basso FG, Hebling J, Souza Costa CA. Concentrations of and application protocols for hydrogen peroxide bleaching gels: effects on pulp cell viability and whitening efficacy. J Dent. 2014;42(2):185-98. 9- Pintado-Palomino K, Peitl Filho O, Zanotto ED, Tirapelli C. A clinical, randomized, controlled study on the use of desensitizing agents during tooth bleaching. J Dent. 2015;43(9):1099-105.

10- Gokay O, Yilmaz F, Akin S, Tunçbilek M, Ertan R. Penetration of the pulp chamber by bleaching agents in teeth restored with various restorative materials. J Endod. 2000;26(2):92-4.

11- Mena-Serrano AP, Parreiras SO, do Nascimento EM, Borges $C P$, Berger $S B$, Loguercio $A D$, et al. Effects of the concentration and composition of in-office bleaching gels on hydrogen peroxide penetration into the pulp chamber. Oper Dent. 2015;40(2):E76-82.

12- Soares DG, Ribeiro AP, Silveira Vargas F, Hebling J, Souza Costa CA. Efficacy and cytotoxicity of a bleaching gel after short application times on dental enamel. Clin Oral Invest. 2013;17(8):1901-9.

13- Oliveira Duque CC, Soares DG, Basso FG, Hebling J, Souza Costa $\mathrm{CA}$. Influence of enamel/dentin thickness on the toxic and esthetic effects of experimental in-office bleaching protocols. Clin Oral Investig. 2017;21(8):2509-20.

14- Soares DG, Basso FG, Hebling J, Souza Costa CA. Immediate and late analysis of dental pulp stem cells viability after indirect exposition to alternative in-office bleaching strategies. Clin Oral Invest. 2015;19(5):1013-20.

15- Vaz MM, Lopes LG, Cardoso PC, Souza JB, Batista AC, Costa NL, et al. Inflammatory response of human dental pulp to at-home and in-office tooth bleaching. J Appl Oral Sci. 2016;24(5):509-17.

16- Ciobanu G, Ion I, Ungureanu L. Testing of pulp vitality by pulsoximetry. Int J Med Dent. 2012;16(2):94-8.

17- Jafarzadeh $\mathrm{H}$, Rosenberg PA. Pulse oximetry: review of a potential aid in endodontic diagnosis. J Endod. 2009;35(3):329-33.

18- Duke $T$, editor. The clinical use of oxygen in hospitals with limited resources: guidelines for health-care workers, hospital engineers and managers. Victoria: World Health Organization; 2019.

19- Gopikrishna V, Tinagupta K, Kandaswamy D. Comparison of electrical, thermal, and pulse oximetry methods for assessing pulp vitality in recently traumatized teeth. J Endod. 2007;33(5):531-5.

20- Kataoka SH, Setzer FC, Gondim-Junior E, Fregnani ER, Moraes $\mathrm{CJ}$, Pessoa OF, et al. Late effects of head and neck radiotherapy on pulp vitality assessed by pulse oximetry. J Endod. 2016;42(6):886-9. 21- Setzer FC, Kataoka SH, Natrielli F, Gondim-Junior E, Caldeira CL. Clinical diagnosis of pulp inflammation based on pulp oxygenation rates measured by pulse oximetry. J Endod. 2012;38(7):880-3.

22- Estrela C, Serpa GC, Alencar AH, Bruno KF, Barletta FB, Felippe $W T$, et al. Oxygen saturation in the dental pulp of maxillary premolars in different age groups - Part 1. Braz Dent J. 2017;28(5):573-7.

23- Bruno KF, Barletta FB, Felippe WT, Silva JA, Goncalves de Alencar $\mathrm{AH}$, Estrela C. Oxygen saturation in the dental pulp of permanent teeth: a critical review. J Endod. 2014;40(8):1054-7.

24- Giovanella LB, Barletta FB, Felippe WT, Bruno KF, Alencar AH, Estrela C. Assessment of oxygen saturation in dental pulp of permanent teeth with periodontal disease. J Endod. 2014;40(12):1927-31.

25- Stella JP, Barletta FB, Giovanella LB, Grazziotin-Soares R, Tovo $M F$, Felippe $W T$, et al. Oxygen saturation in dental pulp of permanent teeth: difference between children/adolescents and adults. J Endod. 2015;41(9):1445-9. 
26- Bargrizan M, Ashari MA, Ahmadi M, Ramezani J. The use of pulse oximetry in evaluation of pulp vitality in immature permanent teeth. Dent Traumatol. 2016;32(1):43-7.

27- Roderjan DA, Stanislawczuk R, Hebling J, Souza Costa CA, Soares DG, Reis $A$, et al. Histopathological features of dental pulp tissue from bleached mandibular incisors. J Mater Sci Eng. 2014;B4(6):178-85. 28- Cartagena AF, Parreiras SO, Loguercio AD, Reis A, Campanha NH. In-office bleaching effects on the pulp flow and tooth sensitivity - case series. Braz Oral Res. 2015;29. pii S1806-83242015000100223.

29- Squier TC. Oxidative stress and protein aggregation during biological aging. Exp Gerontol. 2001;36(9):1539-50.

30- Benetti F, Gomes-Filho JE, Ferreira LL, Sivieri-Araújo G, Ervolino E, Briso $A L$, et al. Concentration-dependent effect of bleaching agents on the immunolabelling of interleukin-6, interleukin-17 and CD5-positive cells in the dental pulp. Int Endod J. 2018;51(7):789-99.

31- Kim S. Regulation of pulpal blood flow. J Dent Res. 1985;64:590-6. 32- Wang J, Wei X, Ling J, Huang Y, Gong Q. Side population increase after simulated transient ischemia in human dental pulp cell. J Endod. 2010;36(3):453-8.

33- Alghaithy RA, Qualtrough AJ. Pulp sensibility and vitality tests for diagnosing pulpal health in permanent teeth: a critical review. Int Endod J. 2017;50(2):135-42.

34- Amemiya $K$, Kaneko $Y$, Muramatsu T, Shimono M, Inoue T. Pulp cell responses during hypoxia and reoxygenation in vitro. Eur $\mathrm{J}$ Oral Sci. 2003;111(4):332-8.

35- Ohzeki H, Takahashi S. Histological pulp changes in the dental osseous segment following anterior maxillary osteotomy. Bull Tokyo Dent Col. $1980 ; 21(1): 21-3$.
36- Cintra LT, Benetti F, Silva Facundo AC, Ferreira LL, Gomes-Filho $J E$, Ervolino $E$, et al. The number of bleaching sessions influences pulp tissue damage in rat teeth. J Endod. 2013;39(12):1576-80.

37- Soares DG, Basso FG, Scheffel DS, Hebling J, Souza Costa CA. Responses of human dental pulp cells after application of a low-concentration bleaching gel to enamel. Arch Oral Biol. 2015;60(9):1428-36.

38- Lima AF, Lessa FC, Mancini MN, Hebling J, Costa CA, Marchi GM. Transdentinal protective role of sodium ascorbate against the cytopathic effects of $\mathrm{H} 2 \mathrm{O} 2$ released from bleaching agents. Oral Surg Oral Med Oral Pathol Oral Radiol Endod. 2010;109(4):e70-6.

39- Aranha AM, Zhang Z, Neiva KG, Costa CA, Hebling J, Nör JE. Hypoxia enhances the angiogenic potential of human dental pulp cells. J Endod. 2010;36(10):1633-7.

40- Lowry OH, Passonneau JV, Hasselberger FX, Schultz DW. Effects of ischemia on known substrates and cofactors of glycolytic pathway in brain. J Biol Chem. 1964;8:18-30.

41- Kim S. Ligamental injection: a physiological explanation of its efficacy. J Endod. 1986;12(10):486-91.

42- Ueno Y, Kitamura C, Terashita M, Nishihara T. Re-oxygenation improves hypoxia-induced pulp cell arrest. J Dent Res. 2006;85(9):8248.

43- Greijer $A E$, van der Wall $E$. The role of hypoxia inducible factor 1 (HIF-1) in hypoxia induced apoptosis. J Clin Pathol. 2004;57(10):100914. 